Health and Prof Dr Robert de Jonge, Dr Gerrit Jansen,

Medicine Ittai Muller MSc, Helen Gosselt MSc

\section{Therapeutic drug monitoring of methotrexate in disease}

Professor Dr Robert de Jonge,
Dr Gerrit Jansen, Ittai Muller
MSc and Helen Gosselt MSc,
Amsterdam University Medical
Center, are pioneering analytical
approaches which can be used
to understand why patients
respond differently to the
anchor drug used to manage
rheumatoid arthritis, called
methotrexate. Their work has
begun to unravel the key factors
behind the mechanism of action
of methotrexate, involving
compounds called methotrexate
polyglutamates, and an enzyme
called folyylpolyglutamate
synthetase. Ultimately, their
research may lead to the
development of personalised
therapy for patients with
rheumatoid arthritis and other
diseases treated with this
drug, including inflammatory
bowel disease.

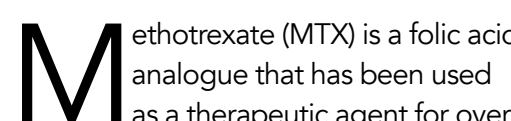

I as a therapeutic agent for over 60 years. It works by stopping cells using folic acid to make building blocks for DNA synthesis, and is often prescribed to patients with certain types of cancers or inflammatory conditions, such as bowel disease (BD). Historically, higher doses of the drug were acute lymphoblastic leukaemia, some solid tumours, and maintenance therapy of childhood leukaemia often includes low-dose oral MTX. Following on from this, methotrexate was then used at low doses to treat chronic autoimmune disorders such as rheumatoid arthritis and Crohn's disease.

Due to its low cost, safety and effectiveness, in addition to its established clinical history, MTX is currently the

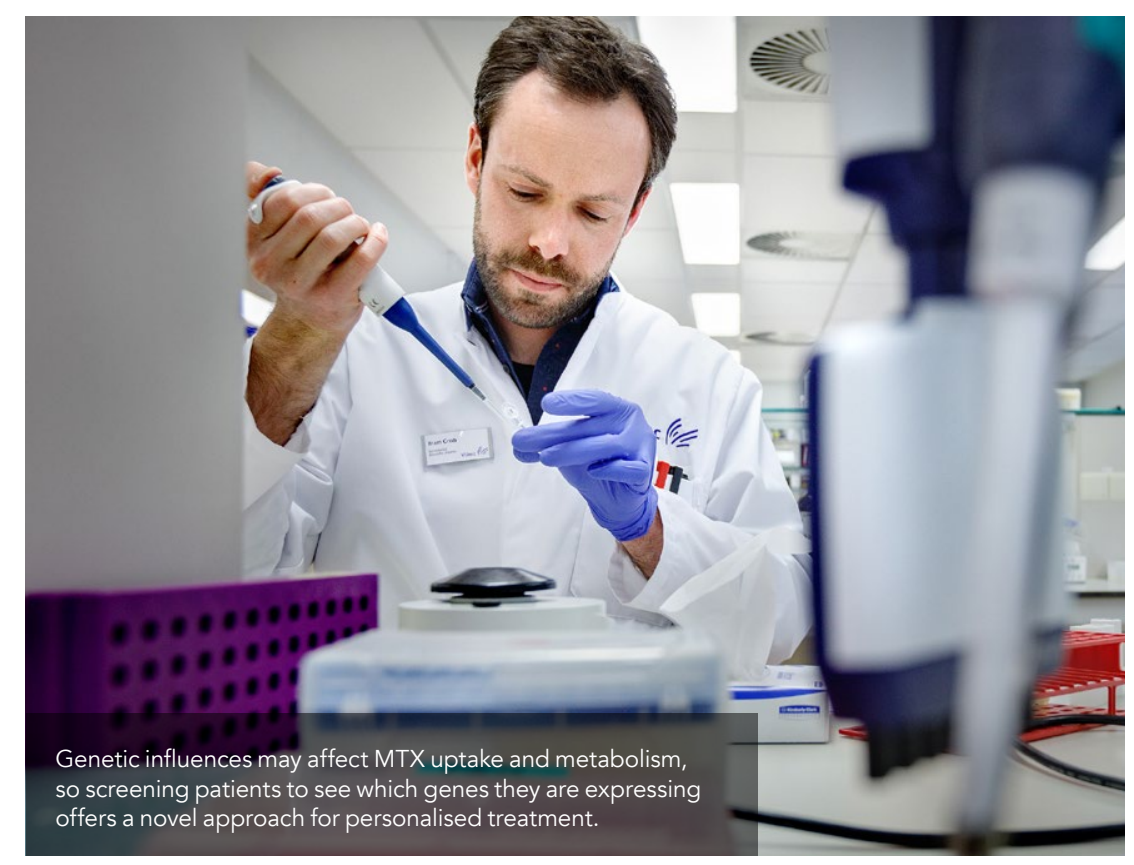

rthritis. However, approximately $40 \%$ of patients with heumatoid arthritis $\mathrm{do}$ not respond to MTX and do not show clinical improvement. Proposed reasons for non-response have included the variation between patients in MTX uptak whor metabolism, non-compliance wh the drug regimen or prescription in process or may occur after an initial esponse to MTX, after 3-6 months of therapy. These patients must then line therapies.

Although a lack of response to MTX may be due to under-dosing, cautio is required when deciding the dose of MTX as uncontrolled increases in dosage risk overdosing patients and may result in toxic side effects. Prediction models to select the right drug at the start of treatment and therapeutic drug monitoring for MTX during the initial stages of treatment who will or will not respond to pate who will or will not respond to the for each individual patient.

There may be also genetic influences on MTX uptake and metabolism, so screening patients to see which genes they are expressing offers a novel approach for personalised treatment. Unfortunately, genetic associations with response to MTX treatment were not consistent, meaning that this is not patients. Another limitation has been the ack of good quality analytical techniques that work on the cell types involved in rheumatoid arthritis.

The reasons for the differences in patient response to MTX are not
fully understood; deepening our understanding of this is the focus (f) Muller MSc, Helen Gosselt MSC, and olleagues at Amsterdam University Medical Center.

THE WAY THAT MTX WORKS The mechanism of action of MTX overlaps with its clinical effectiveness in rheumatoid arthritis and cancer. Following uptake of MTX via a transport protein called the reduced folate carrier, an important step MTX is the conversion of MTX to axtive me conversion of MTX to polyg metabolites called MTXprym Synthetase (FPGS). These MTX PG cannot be export d by cells; a therefore retained in the immune cells which are responsible for driving rheumatoid arthritis, In addition. MTXPGs enhance the potency of the drug by strongly inhibiting enzymes inside the cell. As these enzymes are normally involved in DNA synthesis, their inhibition results in reduced cell proliferation and activation. Fewer activated inflammatory cells means a reduction in clinical symptoms and pain in disease.

THERAPEUTIC DRUG MONITORING Therapeutic drug monitoring of MTX PGs in the bure the level of MTXGs in the blood cells of patients with Pheum Professor Drde Jonge anticipated that higher accumulation of MTX.PG would promote a better response to drug therapy, and a lower level of MTX-PGs may be seen in the nonresponding patients. Leading on from this, it could be hypothesised that the enzyme activity of FPGS could be important, as low FPGS activity would result in a decrease in conversion of MTX to MTX-PGs and hence a poore response to therapy.

In order to achieve this, therapeutic drug monitoring of MTX has been carried out by analysing $M T X$. levels in red blood cells of patients with rheumatoid arthritis whilst they are undergoing MTX
Therapeutic Drug Monitoring (TDM) of Methotrexate (MTX) in disease

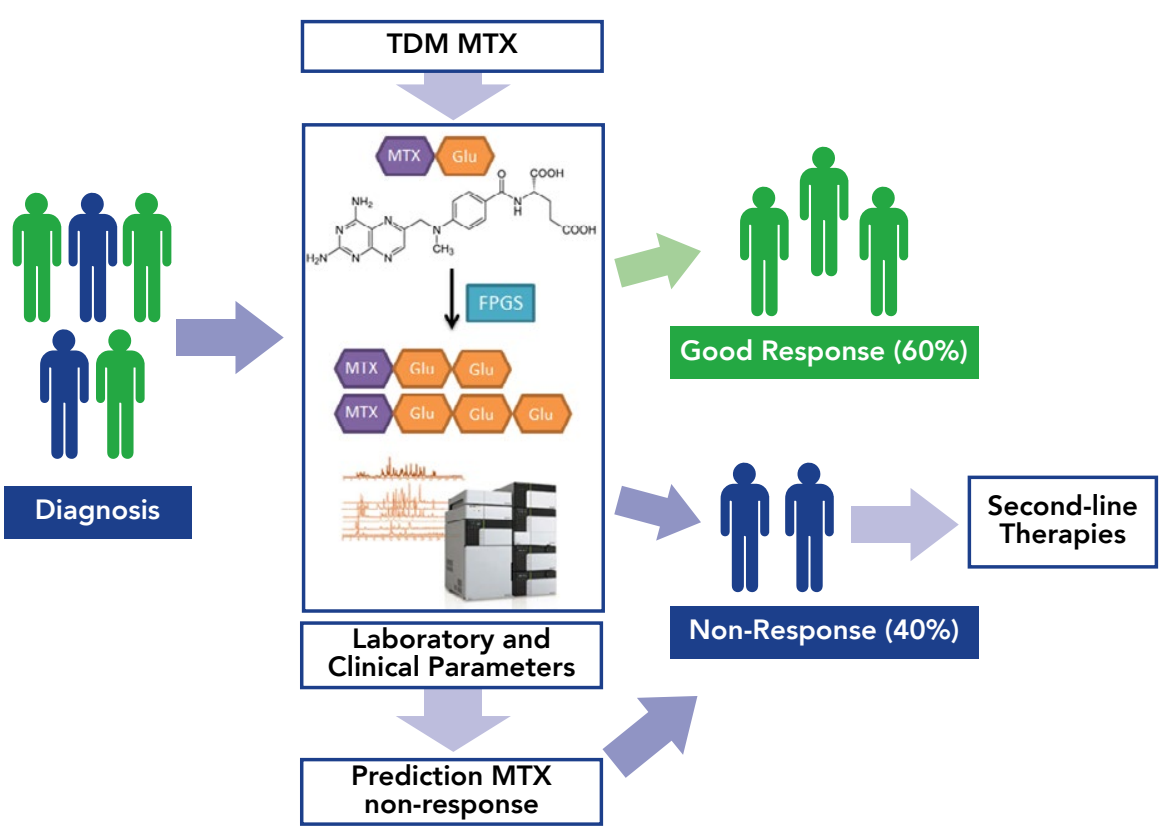

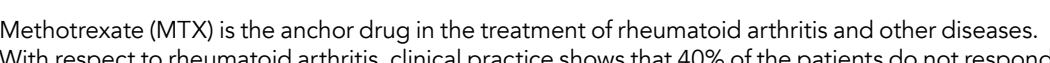
properly to this drug, thus challenging the identification of these patients so that they may switch to second-line therapies as early as possible. Therapeutic drug monitoring of $\mathrm{MTX}$ can be positioned as an
analytical tool to measure methotrexate and its active metabolites, called methotrexate polyglutamates

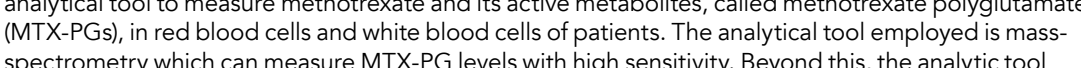
spectrometry which can measure MTX-PG levels with high sensitivity. Beyond this, the analytic tool
can be used to measure the catalytic activity of the enzzyme folylyolyglutamate synthetase (FPSS), responsible for the formation of MTX-PGS. Analyses of MTX-PGs and PPGS activity, along with other
laboratory and clinical parameters, can help to distinguish those patients who do not respond to MTX

Approximately $40 \%$ of patients with rheumatoid arthritis do not respond to MTX and do not show clinical improvement.

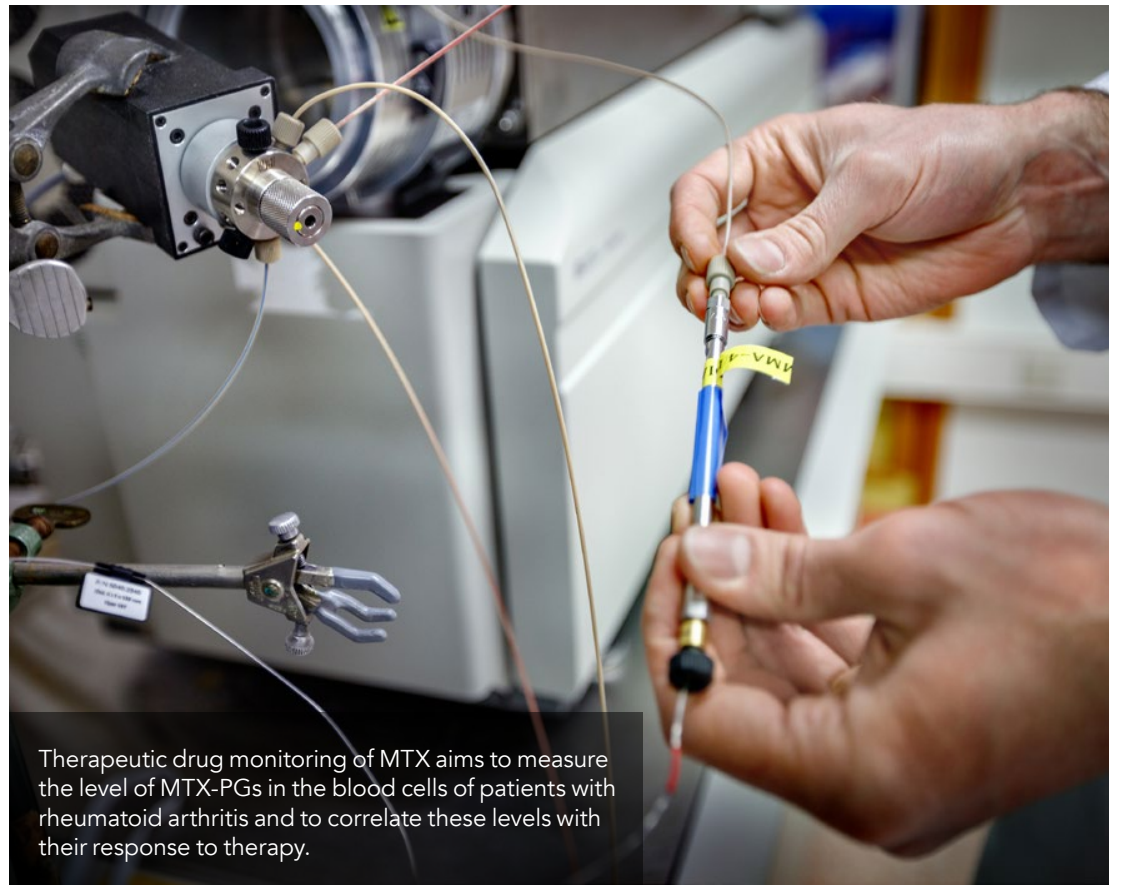




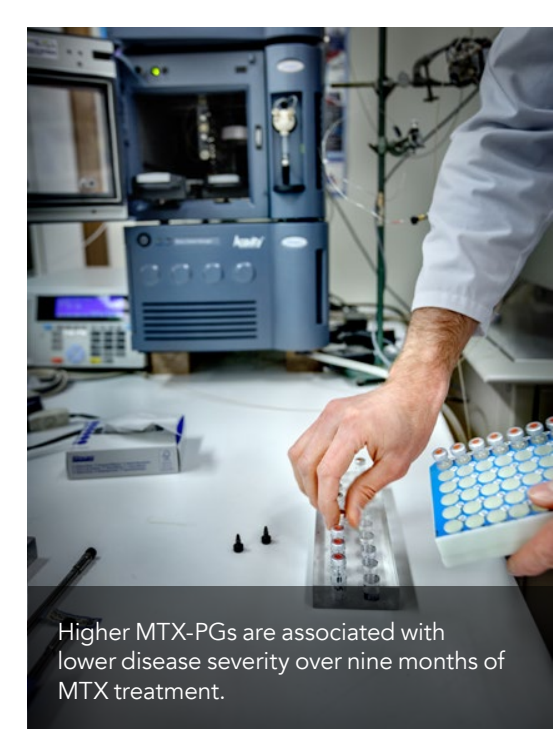

is mass spectrometry, which is a way to identify molecules in a sample by using which arse trique to ppectral patters The results showed that higher MTX PGs were indeed associated with lower disease severity over nine months of MTX treatment but that MTX-PGs were not associated with adverse effects. These findings provide support for the use of MTX-PG concentration in the therapeutic drug monitoring of MTX

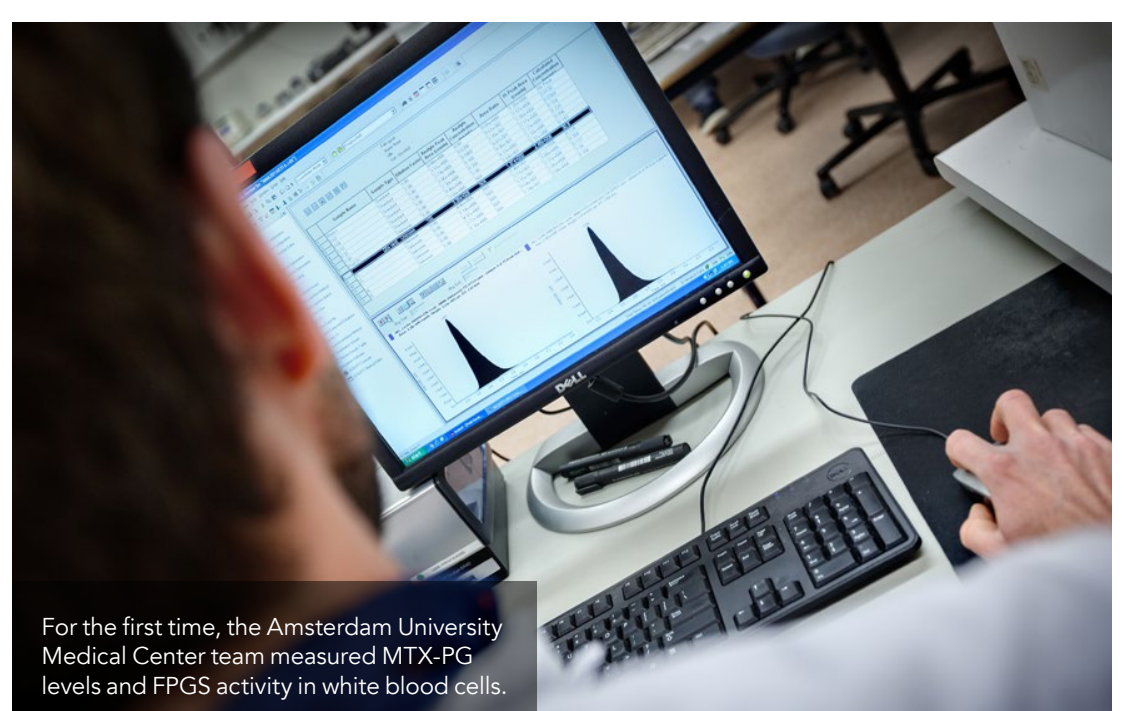

group at Amsterdam University Medica Center has demonstrated the feasibility activity in wite blood cells using mass activy why been done up until this point Prior to this, assessment of FPGS activity and MTX-PG was carried out using assays based on radioactive substances, which were labour intensive and require relatively large numbers of cells. The

advantages of using mass spectrometry Professor $\mathrm{Dr}$ de Jonge suggests that are that no radioactive substances are with low numbers of cells.

previous studies which showed that wither MTX. G level is associated that increasing the dose of MTX and in blood cells. This, alongside the novel mass spectrometry methods they have already established, paves the way for more research into the therapeutic drug response of MTX

Previous studies showed that there was a huge variation in the level of MTX-PGs in fudue therapeutic drug monitoring evel for MTX accumulation in red blood cells and/ patients who were all receiving the exact same dose of MTX to treat their rheumatoid antis. This highlights the need
for personalised therapy regimens, designed to sut individual patients, rather than using a

TARGETING THE RIGHT BLOOD CELLS

Measuring MTX-PG levels in red blood cells acts as a surrogate marker for MTX-PG levels in white blood cells, the cells which are involved in immune and inflammatory responses in rheumatoid arthritis. Thus, rather than measuring MTX-PGs in red blood cells, it would be more relevant to measure MTX-PG levels and PPGS activity directly in white blood cells, especially because loss of MTX activity. Very recent work by the failitate an
optimal response optimal response
to drug treatmen as optimal MTX a "one size fits all' approach. $\quad \begin{aligned} & \text { dose could } \\ & \text { be confirmed }\end{aligned}$

\section{FUTURE PLANS}

Early effective treatment of rheumatoid $\begin{array}{ll}\text { arthritis is important to minimise } & \text { use of MTX. In addition, therapeutic } \\ \text { irreversible damage to joints and long- } & \text { rug monitoring may help to avoid }\end{array}$ term disability, therefore understanding drug monitoring may help to avoid response to MTX can help guide rheumatologists to personalise the patient is identified as a r respond or a non-responder to MTX.

Recently published work by Professor Drde Jonge and colleagues includes on patient features such as age, gende model also incorporates findings from an MTX-prediction model that is based earlier in the treatment process, use of MTX. In addition, therapeutic prescribing unnecessarily high doses need lower doses than others to see improvements in clinical symptoms. Overall, therapeutic drug monitoring contribute to the implementation of prediction models for optimising and personalising MTX therapy in rheumatoid arthritis and other diseases and will help rheumatologists fo prescribe the optimal MTX dose minimal side effects.

\section{Behind the Research} 1.

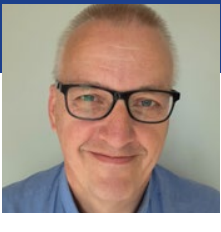

Prof Dr Robert de Jonge

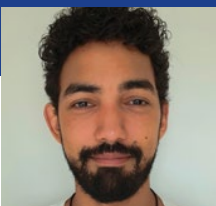

Ittai Muller

E: r.dejonge1@amsterdamumc.n| T: +31-20-4443873 W: www.amsterdamumc.n

\section{Research Objectives}

Robert de Jonge's research aims to set up and implement decision algorithms for the right drug selection and therapeutic drug monitoring (TDM) modalities, combining state-o
optimising drug dosing for personalised therapy.

\section{Detail}

Prof Dr Robert de Jonge, PhD

Department of Clinical Chemistry, Rm PK BR020 Amsterdam University Medical Centers

De Boelelaan 1117, 1081 HV Amsterdam, The Netherland Bio

Robert de Jonge received his PhD in 1999 at the Erasmus registry in Clinical Chemistry. He is now professor and head of the Department of Clinical Chemistry at the

Amsterdam University Medical Center, directing research
programmes on personalised drug treatment.

Funding

Dutch Arthritis Association, Dutch Society for Clinical Chemistry and Laboratory Medicine, Maag Lever Darm Colloror

Collaborators

Clarry Lin, Maurits de Rotte \& Eduard Struys, Dept of Clinica Hematology, Amsterdam UMC • Michael Nurmohamed \& Renske Hebing, Rheumatology Reade, Amsterdam • Willem Lems \& Conny van der Laken, Rheumatology, Amsterdam UMC • Gert Bouma, Nanne de Boer \& Ron Mathôt, Dept Fidder, Bas Oldenburg \& Maartie van de Meeberga of Gastroenterology, UMC Utrecht, NL • Maja Bulatovt Ćalasan, Dept of Internal Medicine, UMC Utrecht, NL

\section{Personal Response}

Do you think these techniques could be expanded for use in therapeutic monitoring of drugs other than methotrexate?

II Our approach is that in inflammatory diseases, first,
one should select the right drug for the right patient at the start of treatment (at diagnosis) by using smart decis response) Once the most modimals tor therape the individual patient is selected, therapeutic drug monitoring of methotrexate or biologics will aid
in reaching the desired anti-inflammatory effect.

\section{References}

Muller, I. B., Lin, M., Struys, E.A., Heydari, P., Hebing,
R.C., Nurmohamed, M. . van der Laken, C., Lems, R.C.F., Nurmohamed, M.T., van der Laken, C., Lems, W.F.,
Cloos, J, Jansen, G. \& de Jonge, R. (2019). Develooment Cloos, J, Jansen, G. \& de Jonge, R. (2019). Developm
and validation of a sensitive UHPLC-MS/MS-based method for the analysis of folylpolyglutamate synthetase
enzymatic activity in peripheral blood mononuclear cells: application in rheumatoid arthritis and leukemia patients. Therapeutic Drug Monitoring, 41(5), 598-606. doi:10.1097

Muller, I.B., Heydari, P., Lin, M., Struys, E.A., Hebing, R., van der Laken, C.J., van Schaardenburg, D.J., Nurmohamed, M.T., Lems, W.F., Cloos, J., Jansen, G. \& de Jonge, R. Ic-ms/ms based method for analysis of enzymmatic activity of folylpolyglutamate synthetase and methotrexate polyglutamates in peripheral blood mononuclear cells of rheumatoid arthritis patients. Annals of the Rheumatic Diseases, 77 (Suppl 2) 1300. doi:10.1136/annrheumdis-2018-
eular5602

Muller, I.B., Hebing, R.F., Jansen, G., Nurmohamed,
M.T. Lems, W.F., Peters, G.J. \& de Jonge, R. (2018), M.T., Lems, W.F., Peters, G.J. \& de Jonge, R. (2018).
Personalized medicine in rheumatoid arthritis: methotrexate polyglutamylation revisited. Expert Review of Precision 123808993.2018.1517025

de Rotte, M.C.F.J., Pluijm, S.M.F., de Jong, P.H.P., Bulatovic J., Hazes, J.M.W. \& de Jonge, R. (2018). Development and validation of a prognostic multivariable model to predict insufficient clinical response to methotrexate in rheumatoid arthritis. PLOS ONE 13(12): e0208534. doi.org/10.1371/
journal.pone 0208534

de Rotte, M.C.F.J, den Boer, E., de Jong, P.H.P., Pluijm, S.M.F., Bulatović Calasan, M., Weel, A.E., Huisman, A.M
Gerards, A.H., van Schaeybroeck, B., Wulffraat, N.M. Gerards, A.H., van Schaeybroeck, B., Wulffraat, N.M.,
Lindemans, J., Hazes, J.M.W. \& de Jonge, R. (2015). Methotrexate polyglutamates in erythrocytes are associated with lower disease activity in patients with rheumatoid
arthritis. Ann Rheum Dis. 74. 408-414. doi:10.1136/ arthritis. Ann Riseum Dis. 74 ,
annrheumdis-2013-203725 